\title{
The impact of COVID-19 lockdown on social network sites use, body image disturbances and self-esteem among adolescents and young women
}

Helena Vall-Roqué ( $\boldsymbol{\sim}$ helena.vall@ub.edu )

University of Barcelona

Ana Andrés

Ramon Llull University, Blanquerna

Carmina Saldaña

University of Barcelona

\section{Research Article}

Keywords: COVID-19, social networks, body image, self-esteem, eating disorders

Posted Date: September 4th, 2020

DOI: https://doi.org/10.21203/rs.3.rs-71386/v1

License: (1) (i) This work is licensed under a Creative Commons Attribution 4.0 International License.

Read Full License

Version of Record: A version of this preprint was published at Progress in Neuro-Psychopharmacology and Biological Psychiatry on August 1st, 2021. See the published version at https://doi.org/10.1016/j.pnpbp.2021.110293. 


\section{Abstract}

This study aimed to determine the impact of COVID-19 lockdown on social network sites (SNS) use and to explore whether SNS use is associated with body image disturbances and low self-esteem. A total of 2601 women living in Spain aged 14-35 years completed questionnaire measures of SNS use, selfesteem, body dissatisfaction and drive for thinness. In the survey, participants were asked about their use of SNS at the moment of answering the survey and before lockdown. A statistically significant increase was found in the frequency of use of all studied SNS (Instagram, YouTube, TikTok, Twitter and Facebook) during lockdown, as well as in the number of women following appearance-focused Instagram accounts. Moreover, significant relationships were found between the frequency of Instagram use and body dissatisfaction, drive for thinness and low self-esteem in the younger age group (14-24), and between the frequency of Instagram use and drive for thinness in the older age group (25-35). Following appearancefocused accounts on Instagram was related to body dissatisfaction and drive for thinness in the younger group, and only to drive for thinness in the older group (25-35). Following appearance-focused accounts on Instagram and a higher frequency of use of Instagram significantly predicted higher levels of drive for thinness. These results suggest that lockdown has had an impact on SNS use, and this might be linked to increased drive for thinness and eating disorder risk among adolescents and young women.

\section{Introduction}

The novel coronavirus disease 2019 (COVID-19) pandemic has posed a significant threat to the global health system worldwide. As stated by the United Nations' report, "although the COVID-19 crisis is, in the first instance, a physical health crisis, it has the seeds of a major mental health crisis as well, if action is not taken" (United Nations 2020).

Several research articles have reported that the COVID-19 outbreak and its associated quarantine might be linked to anxiety, depression, stress, post-traumatic stress disorder and disturbed sleep (e.g. Cao et al. 2020; Liang et al. 2020; Rajkumar 2020). Furthermore, it has been suggested that the pandemic could also have a significant impact on eating disorder risk and symptoms (Rodgers et al. 2020).

The current study was conducted in Spain, which was the third country in the world with more deaths recorded per 100,000 inhabitants when the data for this research was collected, in mid-May (John Hopkins Coronavirus Resource Center 2020). On 14 March, the entire country was placed in strict lockdown, and the Spanish population had to remain at home for at least 6 weeks. On 28 April, the Spanish government announced a lockdown exit strategy for the country, as the number of new cases and deaths in the country showed a decreasing trend. This de-escalation plan started 10 days before the data for this research was collected.

Given the mandated social isolation, the use of social media might have increased during lockdown (Cellini, Canale, Mioni and Costa 2020), and it has been suggested that the use of social networks, especially an appearance-focused use, is linked to body dissatisfaction (Cohen, Newton-John and Slater 
2017; Fardouly and Vartanian 2016; Holland and Tiggemann 2016; Sherlock and Wagstaff 2019) and low self-esteem (Liu and Baumeister 2016; Woods and Scott 2016).

Taking into consideration that social networks play a crucial role in adolescents' and young individuals' lives (Gioia, Griffiths and Boursier 2020; O'Keeffe and Clarke-Pearson 2011), and that body image problems and low self-esteem are more prevalent among girls than boys ( $O^{\prime}$ Dea and Caputi 2001; Magee and Upenieks 2019), special attention should be paid to these groups. Furthermore, women and young individuals are two of the most vulnerable groups to the negative psychosocial effects of COVID-19 (Ozamiz-Etxebarria, Dosil-Santamaria, Picaza-Gorrochategui and Idoiaga-Mondragon 2020; Sun et al. 2020; Wang et al. 2020).

The aim of the present study was to examine the impact of COVID-19 lockdown on social network sites (SNS) use and to explore whether SNS use was associated with body image disturbances and low selfesteem in adolescents and young women. We hypothesized that there would have been a significant increase in the frequency of use of SNS and in the amount of people following appearance-focused Instagram accounts during lockdown, and that the frequency of use of Instagram and following appearance-focused accounts would be positively associated with body dissatisfaction, drive for thinness and low self-esteem. Finally, we theorized that following appearance-focused accounts on Instagram and a higher frequency of use of Instagram would predict higher levels of drive for thinness.

\section{Methods}

\section{Participants and procedure}

A total of 3378 participants from the general population were recruited to participate in a web-based, cross-sectional survey. Inclusion criteria included living in Spain, having between 14 and 35 years old, and being a woman. As the creation of study subgroups was based on age ranges and the other main independent variables of the study were related to SNS usage, participants who did not report their age or did not answer SNS items were excluded from subsequent analyses $(n=261)$. A further 257 participants were excluded as they indicated that they did not live in Spain, and those who were younger than 14 or older than $35(n=128)$, men and participants who identified their gender as "other" $(n=129)$ were excluded. Furthermore, women who indicated that they were pregnant $(n=2)$ were also excluded from subsequent analyses (due to the changes often experienced in body image and self-esteem during pregnancy; Fuller-Tyszkiewicz, Skouteris, Watson and Hill 2013; Inanir, Cakmak, Nacar, Guler and Inanir 2015). This resulted in a final sample of 2601 women.

A cross-sectional and retrospective design was adopted: in the survey, participants were asked to report their use of SNS at the time of answering the survey and before lockdown. Data were collected from the period of May 12 until May 17, 2020. At that time, Spanish population were allowed to engage in individual sport activities for a limited time per day. In 26 provinces (comprising 51\% of the Spanish population), from 11 May it was also permitted to visit friends and family living in the same province, still with social distancing measures. 
Participants were recruited through various social media platforms (Twitter, Instagram and Facebook) and through personal contacts of the research team. Study advertisements outlined that the researchers were interested in understanding the impact of COVID-19 and its associated lockdown on SNS use and mental health.

Respondents to study advertisements clicked on a web link that took them to an online secure internetbased website. Participants gave their informed consent before completing questionnaire measures, and they did not receive compensation for their participation.

The study was approved by the University's Bioethics Commission. Parental consent was not requested as the Spanish law states that it is only required for individuals under 14 years old for this type of studies (Organic Law 3/2018 for Data Protection and Guarantee of Digital Rights, articles 6 and 7).

\section{Measures}

Sociodemographic information. Participants self-reported their age, gender, place of residence, employment situation, relationship status, height, and weight. Height and weight measures were used to calculate body mass index (BMI).

COVID-19 and lockdown-related information. Participants indicated whether they or a close person had contracted COVID-19, and if they had a loved one that had deceased due to COVID-19. Participants also reported if they felt they had a place in their homes where they could relax.

SNS use. Likert-scale self-report items assessed the frequency of use of Instagram, Youtube, TikTok, Twitter and Facebook at the time of answering the survey and before lockdown (I do not have an account on this social network, Never/Almost never, Less than 1 hour/day, 1-2 hours/day, 2-3 hours/day, 3-4 hours/day, More than 4 hours/day). For each social network, answers were grouped into categories based on whether participants exhibited a low, moderate, or high use: Spends less than $1 \mathrm{~h} /$ day, spends between $1 \mathrm{~h}-2 \mathrm{~h} /$ day, and spends more than $2 \mathrm{~h} /$ day. The same categories for each SNS were established for the frequency of use of social networks before lockdown.

Two multiple answer questions queried which type of accounts individuals followed on Instagram at the time of completing the survey and before lockdown, provided that they had an Instagram account. Answers to these questions were recategorized into "following appearance-focused accounts" and "not following appearance-focused accounts". Participants who indicated that they followed fashion, clothing brands, weight-loss tips or diets, beauty, or fitness accounts were included in the first category. Those who did not follow any of the mentioned accounts were included in the second group. Individuals who did not have an Instagram account were not included in any of the categories.

Eating Disorders Inventory-3 (EDI-3; Garner 2004; adapted to Spanish by Elosua, López-Jáuregui and Sánchez-Sánchez, 2010). The Drive for Thinness and Body Dissatisfaction subscales were applied. The former comprises 7 items that assess the desire to be thinner, concern with dieting, preoccupation with weight and fear of weight gain. The latter consists of 10 items that assess discontentment with the 
overall shape and with the size of those regions of the body of extraordinary concern to those with eating disorders. Responses of both subscales are rated on a 6-point Likert scale, ranging from "Never" to "Always". Both scales have an adequate internal consistency: drive for thinness has been reported to have alpha values of .92 in Spanish women, and body dissatisfaction's alpha values were .90 in Spanish women (Elosua et al. 2010).

Rosenberg Self-Esteem Scale (RSES; Rosenberg 1965; adapted to Spanish by Martín-Albo, Núñez, Navarro and Grijalvo 2007). The RSES is a widely used 10-item questionnaire that assesses global selfesteem and general feelings of self-worth with a 4-point Likert scale, ranging from "Strongly disagree" to "Strongly agree". Higher scores indicate higher self-esteem. The scale has been shown to have a onefactor structure and satisfactory levels of internal consistency (Cronbach's alpha of .85) in Spanish samples (Martín Albo et al. 2007).

\section{Data analysis}

Participants were divided into two age categories: generation Z, which comprised individuals that were aged from 14 to 24, and generation Y/Millennials, which included participants that were between 25 and 35 years old. Generational cohorts were established based on Francis and Hoefel (2018) and Duffy, Shrimpton, Clemence, Thomas, Whyte-Smith and Abboud (2018).

Data was analyzed using SPSS version 25. Descriptive statistics (frequency, percentages, mean, and standard deviation) were used for assessing the sociodemographic and COVID-19-related characteristics of the sample, the SNS use variables, and the mental health status of participants. Chi-square tests of independence were performed to examine the relation between age groups and categorical variables, and Student's $t$ tests were conducted to explore the relationship between age groups and the scores in psychological variables. $t$-tests were also performed to examine whether following appearance-focused accounts on Instagram was significantly associated with any of the psychological variables.

One-way ANOVAs were carried out to assess whether the frequency of use of Instagram during lockdown was significantly associated with each psychological variable. If Levene's test of homogeneity of variance was violated, the Brown-Forsyth statistic was reported. Statistically significant effects from the one-way ANOVAs were followed up by Tukey post hoc tests when data met the homogeneity of variances assumption, and by Games-Howell post hoc tests when homogeneity of variances' assumption was violated.

Hedges' $g$ (Hedges and Olkin 1985) was calculated after carrying out Student's $t$ tests and ANOVAs to measure the effect sizes of statistically significant results. Cohen's criteria (Cohen 1988) was used to interpret effect sizes, where $0.2,0.5$ and 0.8 represented small, medium, and large effects, respectively.

A Wilcoxon signed rank test was conducted to assess the differences in frequency of SNS use before and during lockdown, and a McNemar test was carried out to explore the differences in the type of accounts followed on Instagram (appearance-focused or not) before and during lockdown. 
Finally, a hierarchical multiple regression analysis was performed to evaluate whether a high frequency of use of SNS and following appearance-focused accounts on Instagram were able to predict drive for thinness, controlling for age, BMI, and COVID-19-related variables. Preliminary analyses were conducted to ensure no violation of the assumptions of normality, linearity, homoscedasticity, and multicollinearity. Multicollinearity was deemed to be a concern if the variance inflation factor (VIF) coefficient was greater than 10 or tolerance values were less than 0.10 (Belsley, Kuh and Welsch 1980; Hair, Black, Babin and Anderson 2010).

\section{Results}

\section{Descriptive statistics of the sample}

Participants ranged in age from 14 to 35 , with a mean age of 24.05 years (SD $=5.04$ ). 1620 women $(62.3 \%)$ were aged between 14 and 24, and 981 (37.7\%) between 25 and 35. Mean sample BMI was 23.79 $\mathrm{kg} / \mathrm{m}^{2}(\mathrm{SD}=5.07)$. The frequencies and percentages of the other sociodemographic and COVID-19 and lockdown-related variables are reported in table 1 . As shown in the table, statistically significant differences were found between age groups in the following variables: employment situation, relationship status, contraction of COVID-19, and feeling of having a place to relax at home.

Table 1. Participants' sociodemographic, COVID-19 and lockdown-related descriptive statistics divided by age group 


\begin{tabular}{|c|c|c|c|c|}
\hline & $\begin{array}{l}\text { Aged 14-24 } \\
\text { No. (\%) }\end{array}$ & $\begin{array}{l}\text { Aged 25-35 } \\
\text { No. (\%) }\end{array}$ & $\begin{array}{l}\text { Total } \\
\text { No. (\%) }\end{array}$ & $c^{2}$ \\
\hline lace of residence & & & & $c^{2}(1, n=2601)=0.26$ \\
\hline City or town in Spain & $994(61.4)$ & $592(60.3)$ & $1586(61)$ & \\
\hline Rural area in Spain & $626(38.6)$ & $389(39.7)$ & 1015 (39) & \\
\hline mployment status & & & & $c^{2}(4, n=2601)=797.06^{* * *}$ \\
\hline Not working (e.g. student) & $1176(72.6)$ & $160(16.3)$ & $1336(51.4)$ & \\
\hline Employee / Self-employed & $229(14.1)$ & $512(52.2)$ & $741(28.5)$ & \\
\hline Temporary leave & $13(0.8)$ & $43(4.4)$ & $56(2.2)$ & \\
\hline Unemployed & $119(7.3)$ & $149(15.2)$ & $268(10.3)$ & \\
\hline Other & $83(5.1)$ & $117(11.9)$ & $200(7.7)$ & \\
\hline urrent relationship status & & & & $c^{2}(2, n=2601)=235.22 * * *$ \\
\hline Single & $860(53.1)$ & $222(22.6)$ & $1082(41.6)$ & \\
\hline In a relationship / Married & $747(46.1)$ & $752(76.7)$ & $1499(57.6)$ & \\
\hline Other & $13(0.8)$ & $7(0.7)$ & $20(0.8)$ & \\
\hline ontracted COVID-19 & & & & $c^{2}(2, n=2601)=12.52^{* *}$ \\
\hline Yes & $36(2.2)$ & $34(3.5)$ & $70(2.7)$ & \\
\hline No & $1209(74.6)$ & $672(68.5)$ & $1881(72.3)$ & \\
\hline Not sure & $375(23.2)$ & $275(28)$ & $650(25)$ & \\
\hline oved one infected with COVID-19 & & & & $c^{2}(2, n=2601)=1.43$ \\
\hline Yes & $602(37.2)$ & $386(39.3)$ & $988(38)$ & \\
\hline No & $820(50.6)$ & $474(48.3)$ & $1294(49.8)$ & \\
\hline Not sure & $198(12.2)$ & $121(12.3)$ & 319 & \\
\hline oved one deceased due to COVID-19 & & & & $c^{2}(1, n=2601)=0.25$ \\
\hline Yes & $178(11)$ & $114(11.6)$ & $292(11.2)$ & \\
\hline No & $1442(89)$ & $867(88.4)$ & 2309 (88.8) & \\
\hline wn space to relax at home & & & & $c^{2}(1, n=2601)=61.49 * * *$ \\
\hline Yes & $1223(75.5)$ & $598(61)$ & $1821(70)$ & \\
\hline No & $397(24.5)$ & 383 (39) & $780(30)$ & \\
\hline
\end{tabular}

Note. Percentages are presented per column. ${ }^{*} p<.05 ;{ }^{* *} p<.01{ }^{* * *} p<.001$

\section{Psychological status of participants}

Means and standard deviations of the scores in each psychological scale are shown in table 2, together with mean comparisons between age groups. Significant differences between age groups were found in self-esteem and body dissatisfaction, with small effect sizes.

Table 2. Mean scores of psychological measures and comparisons between age groups 


\begin{tabular}{llllll}
\hline & Range & $\begin{array}{l}\text { Aged 14-24 } \\
\text { M (SD) }\end{array}$ & $\begin{array}{l}\text { Aged 25-35 } \\
\text { M (SD) }\end{array}$ & $t$ & Hedges' $g$ [95\% CI] \\
& $10-40$ & $26.86(6.42)$ & $28.61(6.43)$ & $-6.43^{* * * *}$ & $0.27[0.19 ; 0.36]$ \\
\hline Self-esteem & & & & & \\
\hline Body dissatisfaction & $0-40$ & $16.39(9.9)$ & $17.38(10.9)$ & $-2.26^{*}$ & $-0.20[-0.28 ;-0.11]$ \\
\hline Drive for thinness & $0-28$ & $10.99(8.56)$ & $10.57(8.13)$ & 1.23 & \\
& & & & & \\
\hline
\end{tabular}

Note. Sample sizes differ among questionnaires as not all participants completed all measures. EDI-3 was fulfilled by 2471 women and RSES by 2357 women. ${ }^{*} p<.05 ; * * p<.01 ; * * * p<.001$

\section{Social network sites use}

Statistically significant differences were found between age groups in the frequency of use of all social networks (Instagram: $\chi^{2}=24.75, p<.001$; Youtube: $\chi^{2}=29.94, p<.001$; TikTok: $\chi^{2}=39.28, p<.001$; Twitter: $\chi^{2}=145.46, p<.001$; Facebook: $\left.\chi^{2}=66.18, p<.001\right)$, with generation $Z$ being the ones who use Instagram, Youtube, TikTok, and Twitter more frequently, and Generation $Y$ the ones who use Facebook more often. On the other hand, the proportion of women following appearance-focused accounts on Instagram did not significantly differ between the two age groups.

Changes in the frequency of SNS use before and during lockdown

When comparing the frequency of use of SNS before lockdown and at the moment of answering the survey, a Wilcoxon Signed Rank Test revealed a statistically significant increase in frequency of use of all studied social networks: Instagram $(z=-27.68, p<.001)$, Youtube $(z=-18.68, p<.001)$, TikTok $(z=-23.01$, $p<.001)$, Twitter $(z=-17.54, p<.001)$, and Facebook $(z=-13.01, p<.001)$. When assessed separately, these statistically significant results were found both for the Generation $Y$ and the Generation $Z$ age groups.

Changes in the type of accounts followed on Instagram before and during lockdown

A McNemar test revealed a statistically significant difference in the proportion of participants following appearance-focused accounts on Instagram across the two self-reported time periods $\left(\chi^{2}=42.15, p<\right.$ $.001)$, indicating that there was a statistically significant increase in the amount of women following appearance-centered accounts during lockdown compared to before lockdown. When assessed separately, these statistically significant differences were found for both age groups.

\section{Relationship between the use of SNS and self-esteem, body dissatisfaction and drive for thinness}

\section{Frequency of Instagram use and psychological variables}

One-way ANOVA results are shown in table 3. Frequency of Instagram use was significantly related to self-esteem, body dissatisfaction and drive for thinness in the younger age group. Post-hoc analyses 
indicated that participants who spent more than two hours per day using Instagram had significantly higher levels of body dissatisfaction and drive for thinness, and significantly lower levels of self-esteem, compared to those who reported using Instagram between one and two hours per day.

Regarding the sample aged 25-35, the frequency of Instagram use was significantly associated with drive for thinness. Post-hoc analyses revealed that those who used Instagram for more than two hours per day exhibited significantly higher levels of drive for thinness than those who reported using Instagram less than one hour per day.

As shown in table 3, effect sizes were found to be small.

Table 3. Mean comparisons in psychological measures according to the frequency of use of Instagram during lockdown

\section{Aged 14-24}

\section{Aged 25-35}

\begin{tabular}{|c|c|c|c|c|c|c|c|c|}
\hline & $\begin{array}{l}\text { Less than } \\
\text { 1h/day } \\
\text { M (SD) }\end{array}$ & $\begin{array}{l}1 \mathrm{~h}- \\
2 \mathrm{~h} / \text { day } \\
\mathrm{M} \\
(\mathrm{SD})\end{array}$ & $\begin{array}{l}\text { More than } \\
\text { 2h/day } \\
\text { M (SD) }\end{array}$ & $\begin{array}{l}\text { ANOVA } \\
\text { Hedges' } g[95 \% \\
\text { CI] }\end{array}$ & $\begin{array}{l}\text { Less than } \\
\text { 1h/day } \\
\text { M (SD) }\end{array}$ & $\begin{array}{l}\mathrm{h}- \\
2 \mathrm{~h} / \text { day } \\
\mathrm{M}(\mathrm{SD})\end{array}$ & $\begin{array}{l}\text { More } \\
\text { than } \\
\text { 2h/day } \\
\text { M (SD) }\end{array}$ & $\begin{array}{l}\text { ANOVA } \\
\text { Hedges' } g[95 \% \\
\text { CI }]\end{array}$ \\
\hline Self-esteem & $\begin{array}{l}26.44 \\
(6.9)\end{array}$ & $\begin{array}{l}27.49 \\
(6.3)\end{array}$ & $\begin{array}{l}26.56 \\
(6.38)\end{array}$ & $\begin{array}{l}F(2, \\
1454)=3.71^{*} \\
g=0.15[0.03 \\
0.26]\end{array}$ & $\begin{array}{l}29.29 \\
(6.89)\end{array}$ & $\begin{array}{l}28.89 \\
(6.27)\end{array}$ & $\begin{array}{l}28.11 \\
(6.37)\end{array}$ & $F(2,878)=2.33$ \\
\hline $\begin{array}{l}\text { Body } \\
\text { dissatisfaction }\end{array}$ & $\begin{array}{l}16.72 \\
(10.14)\end{array}$ & $\begin{array}{l}15.47 \\
(9.66)\end{array}$ & $\begin{array}{l}16.9 \\
(9.98)\end{array}$ & $\begin{array}{l}F(2, \\
1520)=3.54^{*} \\
g=-0.15[-0.25 \\
-0.04]\end{array}$ & $\begin{array}{l}16.47 \\
(10.94)\end{array}$ & $\begin{array}{l}17.03 \\
(11.11)\end{array}$ & $\begin{array}{l}18.06 \\
(10.67)\end{array}$ & $F(2,926)=1.54$ \\
\hline $\begin{array}{l}\text { Drive for } \\
\text { thinness }\end{array}$ & $\begin{array}{l}10.48 \\
(8.24)\end{array}$ & $\begin{array}{l}10.16 \\
(8.31)\end{array}$ & $\begin{array}{l}11.68 \\
(8.75)\end{array}$ & $\begin{array}{l}F_{\mathrm{BF}}(2, \\
1520)=5.71 * * \\
g=-0.18[-0.29 \\
-0.07]\end{array}$ & $9.6(7.74)$ & $\begin{array}{l}10.06 \\
(8.05)\end{array}$ & $\begin{array}{l}11.39 \\
(8.3)\end{array}$ & $\begin{array}{l}F(2, \\
926)=3.98 * \\
g=-0.22[-0.40 ; \\
-0.04]\end{array}$ \\
\hline
\end{tabular}

Note. BF $=$ Brown-Forsythe. ${ }^{*} p<.05 ; * * p<.01 ; * * * p<.001$

Following of appearance-focused accounts on Instagram and psychological measures

As reported in table 4, participants that were aged between 14 and 24 years old who followed appearance-centered Instagram accounts had significantly higher scores in body dissatisfaction and drive for thinness compared to those who reported to follow other types of accounts on Instagram. Regarding the Millennials age group, these statistically significant differences depending on the accounts followed on Instagram were only found for drive for thinness. Effect sizes were small.

Table 4. Mean comparisons in psychological measures according to the type of accounts followed on Instagram during lockdown 


\begin{tabular}{|c|c|c|c|c|c|c|}
\hline & Aged 14-24 & & & Aged 25-35 & & \\
\hline & $\begin{array}{l}\text { Following } \\
\text { appearance } \\
\text { accounts } \\
\text { M (SD) }\end{array}$ & $\begin{array}{l}\text { Not following } \\
\text { appearance } \\
\text { accounts } \\
\text { M (SD) }\end{array}$ & $\begin{array}{l}t \\
\text { Hedges' } g \\
{[95 \% \mathrm{CI}]}\end{array}$ & $\begin{array}{l}\text { Following } \\
\text { appearance } \\
\text { accounts } \\
\text { M (SD) }\end{array}$ & $\begin{array}{l}\text { Not following } \\
\text { appearance } \\
\text { accounts } \\
\text { M (SD) }\end{array}$ & $\begin{array}{l}t \\
\text { Hedges' } g \\
{[95 \% \mathrm{CI}]}\end{array}$ \\
\hline Self-esteem & $27.01(6.29)$ & $26.6(6.73)$ & -1.1 & $28.58(6.42)$ & $28.68(6.47)$ & 0.22 \\
\hline $\begin{array}{l}\text { Body } \\
\text { dissatisfaction }\end{array}$ & $16.81(9.95)$ & $15.36(9.75)$ & $\begin{array}{l}-2.65^{* *} \\
g=0.15 \\
{[0.04 ;} \\
0.26]\end{array}$ & $17.72(10.76)$ & $16.67(11.13)$ & -1.37 \\
\hline $\begin{array}{l}\text { Drive for } \\
\text { thinness }\end{array}$ & $11.76(8.61)$ & $9.24(8.21)$ & $\begin{array}{l}-5.43 * * * \\
g=0.30 \\
{[0.19} \\
0.41]\end{array}$ & $11.42(8.28)$ & $8.81(7.55)$ & $\begin{array}{l}-4.77 * * * \\
g=0.32 \\
{[0.19} \\
0.46]\end{array}$ \\
\hline
\end{tabular}

Note. ${ }^{*} p<.05 ;{ }^{* \star} p<.01 ;{ }^{* \star *} p<.001$

\section{Social network sites use as a predictor of drive for thinness}

Results from the hierarchical multiple regression analysis can be found in table 5. Multicollinearity was judged to not be a problem (tolerance $\geq 0.89, \mathrm{VIF} \leq 1.13$ ), and the other preliminary analyses ensured no violation of the assumptions of normality, linearity, and homoscedasticity.

Results from step 1 in the regression analysis indicated that age and BMI were significant predictors of drive for thinness (age: $\beta=-0.10, p<.001$; BMI: $\beta=0.34, p<.001$ ), explaining $10.8 \%$ of its variance. After controlling for these two variables, COVID-19 and lockdown-related measures accounted for $0.4 \%$ of the variance in drive for thinness, and the total variance explained by the model was $11.2 \%(F(6,2453)=$ $51.68, p<.001)$. Only the variable 'having a place to relax at home' significantly predicted drive for thinness $(\beta=0.06, p<.01)$. In step 3 , the regression analyses revealed that both the frequency of use of Instagram and following appearance-focused accounts on Instagram were significant predictors of drive for thinness (respectively, $\beta=0.06, p<.01$, and $\beta=0.13, p<.001$ ). These variables explained an additional $2.3 \%$ of the variance in drive for thinness, and the total variance explained by the model as a whole was $13.5 \%(F(8,2451)=47.85, p<.001)$.

Following appearance-focused accounts on Instagram was the second strongest predictor of drive for thinness, as it was observed when the standardized regression coefficients in step 3 of the regression analysis were compared.

Table 5. Hierarchical multiple regression analysis predicting drive for thinness 
Drive for thinness

\begin{tabular}{|c|c|c|}
\hline Step and predictor & $\overline{\mathrm{R}^{2} \quad \Delta \mathrm{F}}$ & $\beta$ \\
\hline Step 1 & $0.11148 .4 * *$ & \\
\hline Age & & $-0.10 * * *$ \\
\hline BMI & & $0.34 * * *$ \\
\hline Step 2 & $0.113 .07 *$ & \\
\hline Age & & $-0.11 * * *$ \\
\hline BMI & & $0.34^{* * *}$ \\
\hline Contracted COVID-19 & & 0.04 \\
\hline Loved one contracted COVID-19 & & 0.003 \\
\hline Loved one deceased by COVID-19 & & -0.01 \\
\hline Having own space to relax & & $0.06^{* *}$ \\
\hline Step 3 & $0.1432 .39 * *$ & \\
\hline Age & & $-0.10^{* * *}$ \\
\hline BMI & & $0.34^{* * *}$ \\
\hline Contracted COVID-19 & & 0.03 \\
\hline Loved one contracted COVID-19 & & 0.01 \\
\hline Loved one deceased by COVID-19 & & -0.01 \\
\hline Having own space to relax & & $0.06^{* *}$ \\
\hline Frequency of use of Instagram & & $0.06^{* *}$ \\
\hline Following appearance-focused accounts on Instagram & & $0.13 * * *$ \\
\hline
\end{tabular}

Note. $\mathrm{BMI}=$ Body Mass Index. ${ }^{*} p<.05 ;{ }^{* *} p<.01 ;{ }^{* * *} p<.001$

\section{Discussion}

The aim of this study was to explore the impact of COVID-19 lockdown on SNS use, body image disturbances and self-esteem in a community sample of female Spanish youngsters.

Significant differences were found between age groups, not only in some of the sociodemographic characteristics but also in the frequency of use of SNS and in self-esteem and body dissatisfaction. The differences found in SNS use go in accordance with other studies (e.g. Adobe 2019), which have revealed that Facebook has experienced a decline in usage among generation $Z$, while other SNS like Instagram and YouTube have taken the lead. Regarding the psychological variables, it has been stated that selfesteem follows an inverted U-shape over the life course (Orth, Erol and Luciano 2018), which aligns with the differences found in the present study. However, mixed findings have been reported regarding the relationship between body dissatisfaction and age: even though some authors have indicated that youth are increasingly dissatisfied with their bodies as their BMI increases from middle school to young adulthood (Bucchianeri, Arikian, Hannan, Eisenberg and Neumark-Sztainer 2013), others have reported that body dissatisfaction remains relatively stable across the life span (Tiggemann 2004). Hence, further research should aim at examining the differences in body dissatisfaction among age groups. 
As hypothesized, there was a significant increase in the frequency of use of SNS and in the number of girls following appearance-centered accounts on Instagram during lockdown. This might be a consequence of forced social distancing, and aligns with KalaGato's report (KalaGato 2020), which concludes that average time spent on social media surged during lockdown. This increase may have allowed users to widen the topics range of the followed accounts on Instagram.

The frequency of use of Instagram was positively associated with body dissatisfaction, drive for thinness and low self-esteem among Generation Z participants. In the Generation Y group, the frequency of use of Instagram was only associated with drive for thinness. However, effect sizes were very small, hence these results should be interpreted with caution. Following appearance-focused accounts on Instagram was found to be associated with drive for thinness in both age groups, and the effect size in this case was stronger, even though still small. Our hypothesis stating that following appearance-focused accounts on Instagram and a higher frequency of use of Instagram would predict higher levels of drive for thinness was confirmed. These results align with previously published literature (Cohen et al. 2017; Holland and Tiggemann 2016; Sherlock and Wagstaff 2019). Taking into consideration the lockdown's associated changes in SNS use stated above, these results might have significant implications, as they might indicate that the detrimental effects of SNS could have been exacerbated during the pandemic, and COVID-19 might be linked to increased drive for thinness and risk for eating disorder behaviors relative to media effects, as suggested by Rodgers et al. (2020).

The current study has several limitations that should be noted. First, only women were included in the study. Further research should aim at examining the impact of lockdown on men and individuals who do not identify within the gender binary system. Second, as participants' recruitment was conducted online, the sample of the present study is not representative of the Spanish population. Third, causality cannot be assumed among variables as the study had a cross-sectional design. Even though the retrospective design has been found to be a valuable alternative to traditional pretest-posttest design as it addresses many of its validity concerns and mitigates the response shift bias that seems ubiquitous in the traditional approach, criticisms of the retrospective design include memory-related problems, impression management and response bias (Little et al. 2020).

It should also be taken into consideration that when the study was conducted there was greater freedom of movement in Spain compared to the initial weeks of lockdown. Hence, data collection does not correspond with the contagious peak.

In conclusion, COVID-19 lockdown seems to have had an impact on SNS use, which might involve an increase in body image disturbances among adolescents and young women. Further research should aim at examining the impact of the pandemic on eating disorders, and early strategies should be implemented in order to mitigate the adverse effects of COVID-19.

\section{Declarations}

Funding: This research did not receive any specific grant from funding agencies. 
Conflicts of interest: The authors declare that they have no conflict of interest.

Ethics approval: This study was performed in line with the principles of the Declaration of Helsinki. Approval was granted by the Bioethics Committee of the University of the first and third authors.

Consent to participate: Informed consent was obtained from all participants included in the study. Parental consent was not requested as the Spanish law (Organic Law 3/2018) states that it is only required for individuals under 14 years old for this type of studies.

Consent for publication: Participants signed informed consent regarding publishing the results of the study.

Availability of data: The datasets generated during and/or analyzed during the current study are available from the corresponding author on reasonable request.

Code availability: Not applicable.

Authors' contributions: All authors contributed to the study conception and design. Material preparation, data collection and analysis were performed by all authors. The first draft of the manuscript was written by Helena Vall-Roqué and all authors commented on previous versions of the manuscript. All authors read and approved the final manuscript.

\section{References}

Adobe. (2019). Voices of the generations: An Adobe advertising research report. Adobe. https://www.adobe.com/content/dam/www/us/en/avstg/pdfs/voiceofgenerations.pdf. Accessed 15 June 2020

Belsley, D. A., Kuh, E., \& Welsch, R. E. (1980). Regression diagnostics: Identifying influential data and sources of collinearity. Chichester: Wiley.

Bucchianeri, M.M., Arikian, A.J., Hannan, P.J., Eisenberg, M.E., \& Neumark-Sztainer, D. (2013). Body dissatisfaction from adolescence to young adulthood: Findings from a 10-year longitudinal study. Body Image, https://doi.org/10.1016/j.bodyim.2012.09.001

Cao, W., Fang, Z., Hou, G., Han, M., Xu, X., Dong, J., \& Zheng, J. (2020). The psychological impact of the COVID-19 epidemic on college students in China. Psychiatry Research, https://doi.org/10.1016/j.psychres.2020.112934

Cellini, N., Canale, N., Mioni, G., \& Costa, S. (2020). Changes in sleep pattern, sense of time and digital media use during COVID-19 lockdown in Italy. Journal of Sleep Research, https://doi.org/10.1111/jsr.13074 
Cohen, J. (1988). Statistical power analysis for the behavioral sciences, 2nd Ed. Hillsdale: Lawrence Erlbaum.

Cohen, R., Newton-John, T., \& Slater, A. (2017). The relationship between Facebook and Instagram appearance-focused activities and body image concerns in young women. Body Image, https://doi.org/10.1016/j.bodyim.2017.10.002

Duffy, B., Shrimpton, H., Clemence, M., Thomas, F., Whyte-Smith, H., \& Abboud, T. (2018). Beyond binary: The lives and choices of generation Z. London: Ipsos Mori.

Elosua, P., López-Jáuregui, A., \& Sánchez-Sánchez, F. (2010). Adaptación española del Eating Disorder Inventory-3. Normalización y validación [Spanish adaptation of the Eating Disorder Inventory-3. Standardization and validation]. Madrid: TEA.

Fardouly, J., \& Vartanian, L.R. (2016). Social media and body image concerns: current research and future directions. Current Opinion in Psychology, https://doi.org/10.1016/j.copsyc.2015.09.005

Francis, T., \& Hoefel, F. (2018). 'True Gen': Generation Z and its implications for companies. McKinsey\&Company. https://www.mckinsey.com/industries/consumer-packaged-goods/ourinsights/true-gen-generation-z-and-its-implications-for-companies\#. Accessed 15 May 2020.

Fuller-Tyszkiewicz, M., Skouteris, H., Watson, B. E., \& Hill, B. (2013). Body dissatisfaction during pregnancy: A systematic review of cross-sectional and prospective correlates. Journal of Health Psychology, https://doi.org/10.1177/1359105312462437

Garner, D. M. (2004). Eating Disorder Inventory-3, Professional Manual. Odessa: Psychological Assessment Resources.

Gioia, F., Griffiths, M.D., \& Boursier, V. (2020) Adolescents' body shame and social networking sites: The mediating effect of body image control in photos. Sex Roles, https://doi.org/10.1007/s11199-020-011420

Hair, J.F., Black, W.C., Babin, B.J., \& Anderson, R.E. (2010). Multivariate data analysis, 7th Ed. New Jersey: Prentice Hall.

Hedges, L.V., \& Olkin, I. (1985). Statistical methods for meta-analysis. Orlando: Academic Press.

Holland, G., \& Tiggemann, M. (2016). A systematic review of the impact of the use of social networking sites on body image and disordered eating. Body Image, https://doi.org/10.1016/j.bodyim.2016.02.008

Inanir, S., Cakmak, B., Nacar, M. C., Guler, A. E., \& Inanir, A. (2015). Body image perception and self-esteem during pregnancy. International Journal of Women's Health and Reproduction Sciences, https://doi.org/10.15296/ijwhr.2015.41 
John Hopkins University \& Medicine. (2020). How is the outbreak growing?

https://coronavirus.jhu.edu/data/cumulative-cases Accessed 20 August 2020.

KalaGato. (2020). COVID-19 digital impact: A boon for social media. Kalagato. https://www.mediabrief.com/kalagato-vocid-19-digital-impact-report-part-1/ Accessed 2 July 2020

Liang, L., Ren, H., Cao, R., Hu, Y., Qin, Z., Li, C., \& Mei, S. (2020). The effect of COVID-19 on youth mental health. Psychiatric Quarterly, https://doi.org/10.1007/s11126-020-09744-3

Little, T.D., Chang, R., Gorrall, B.K., Waggenspack, L., Fukuda, E., Allen, P.J., \& Noam, G.G. (2020). The retrospective pretest-posttest design redux: On its validity as an alternative to traditional pretestposttest measurement. International Journal of Behavioral Development, https://doi.org/10.1177/0165025419877973

Liu, D., \& Baumeister, R.F. (2016). Social networking online and personality of self-worth: A meta-analysis. Journal of Research in Personality, https://doi.org/10.1016/j.jrp.2016.06.024

Magee, W., \& Upenieks, L. (2019). Gender differences in self-esteem, unvarnished self-evaluation, future orientation, self-enhancement and self-derogation in a U.S. national sample. Personality and Individual Differences, https://doi.org/10.1016/j.paid.2019.05.016

Martín-Albo, J., Núñez, J. L., Navarro, J. G., \& Grijalvo, F. (2007). The Rosenberg self-esteem scale: Translation and validation in university students. The Spanish Journal of Psychology, https://doi.org/10.1017/S1138741600006727

O'Dea, J. A., \& Caputi, P. (2001). Association between socioeconomic status, weight, age and gender, and the body image and weight control practices of 6- to 19-year-old children and adolescents. Health Education Research, https://doi.org/10.1093/her/16.5.521

O'Keeffe, G. S., \& Clarke-Pearson, K. (2011). The impact of social media on children, adolescents, and families. Pediatrics, https://doi.org/10.1542/peds.2011-0054

Orth, U., Erol, R.Y., \& Luciano, E.C. (2018). Development of self-esteem from age 4 to 94 years: A metaanalysis of longitudinal studies. Psychological Bulletin, http://dx.doi.org/10.1037/bul0000161

Ozamiz-Etxebarria, N., Dosil-Santamaria, M., Picaza-Gorrochategui, M., \& Idoiaga-Mondragon, N. (2020). Stress, anxiety, and depression levels in the initial stage of the COVID-19 outbreak in a population sample in the northern Spain [Niveles de estrés, ansiedad y depresión en la primera fase del brote del COVID-19 en una muestra recogida en el norte de Esp. Cadernos de Saude Publica, https://doi.org/10.1590/0102$311 \times 00054020$

Rajkumar, R. P. (2020). COVID-19 and mental health: A review of the existing literature. Asian Journal of Psychiatry, https://doi.org/10.1016/j.ajp.2020.102066 
Rodgers, R.F., Lombardo, C., Cerolini, S., Franko, D.L., Omori, M., Fuller-Tyszkiewicz, M., Linardon, J., Courtet, P., \& Guillaume, S. (2020). The impact of the COVID-19 pandemic on eating disorder risk and symptoms. International Journal of Eating Disorders, https://doi.org/10.1002/eat.23318

Rosenberg, M. (1965). Society and the Adolescent Self-Image. Princeton: Princeton University Press.

Sherlock, M., \& Wagstaff, D.L. (2019). Exploring the relationship between frequency of Instagram use, exposure to idealized images, and psychological well-being in women. Psychology of Popular Media Culture, https://doi.org/10.1037/ppm0000182

Sun, L., Sun, Z., Wu, L., Zhu, Z., Zhang, F., Shang, Z., Jia, Y., Gu, J., Zhou, Y., Wang, Y., Liu, N., \& Liu, W. (2020). Prevalence and risk factors of acute posttraumatic stress symptoms during the COVID-19 outbreak in Wuhan, China. MedRxiv, https://doi.org/10.1101/2020.03.06.20032425

Tiggemann, M. (2004). Body image across the adult life span: stability and change. Body Image, https://doi.org/10.1016/S1740-1445(03)00002-0

United Nations. (2020). Policy Brief: COVID-19 and the Need for Action on Mental Health. United Nations. https://unsdg.un.org/sites/default/files/2020-05/UN-Policy-Brief-COVID-19-and-mental-health.pdf. Accessed 5 August 2020

Wang, C., Pan, R., Wan, X., Tan, Y., Xu, L., Ho, C. S., \& Ho, R. C. (2020). Immediate psychological responses and associated factors during the initial stage of the 2019 coronavirus disease (COVID-19) epidemic among the general population in China. International Journal of Environmental Research and Public Health, https://doi.org/10.3390/ijerph17051729

Woods, H.C., \& Scott, H. (2016). \#Sleepyteens: Social media use in adolescence is associated with poor sleep quality, anxiety, depression and low self-esteem. Journal of Adolescence, https://doi.org/10.1016/j.adolescence.2016.05.008 